\title{
Gas-phase advanced oxidation (GPAO) for benzene-containing gas by an ultraviolet irradiation/hydrogen peroxide vapour $\left(\mathrm{UV} /\left[\mathrm{H}_{2} \mathrm{O}_{2}\right]_{\mathrm{g}}\right)$ process
}

\author{
Yuping Jiang ${ }^{1} \odot$. Juanjuan Song ${ }^{1} \cdot$ Andong $\mathrm{Zhu}^{1}$
}

Received: 6 February 2021 / Accepted: 3 October 2021 / Published online: 14 October 2021

(c) The Author(s), under exclusive licence to Springer-Verlag GmbH Germany, part of Springer Nature 2021

\begin{abstract}
Hydrogen peroxide $\left(\mathrm{H}_{2} \mathrm{O}_{2}\right)$ is a remarkably strong oxidant, and its vapour $\left(\left[\mathrm{H}_{2} \mathrm{O}_{2}\right]_{\mathrm{g}}\right)$ has further advantages, such as a low cost and good light transmission. However, there has been very little research on its removal through gas-phase advanced oxidation (GPAO). In the present study, the photochemical oxidation of a gas that contains a series of benzene derivatives using ultraviolet (UV) irradiation and $\left[\mathrm{H}_{2} \mathrm{O}_{2}\right]_{\mathrm{g}}$ was investigated in a transparent bag made of fluorinated ethylene propylene (FEP). UV and $\left[\mathrm{H}_{2} \mathrm{O}_{2}\right]_{\mathrm{g}}$ barely reduced the pollutant within $5 \mathrm{~h}$ when used alone, and the reactant was also stable. When the pollutant concentration was high $\left(248\right.$ to $756 \mathrm{mg} / \mathrm{m}^{3}$ ) and the residence time was short $(3 \mathrm{~s}$ ) compared with related studies on the removal of benzene, toluene and xylene, the apparent removal rate by $\mathrm{UV} /\left[\mathrm{H}_{2} \mathrm{O}_{2}\right]_{\mathrm{g}} /($ powder active carbon, PAC) was higher than when other methods $\left(\mathrm{UV} /\left[\mathrm{H}_{2} \mathrm{O}_{2}\right]_{\mathrm{g}}, \mathrm{UV} /\left[\mathrm{H}_{2} \mathrm{O}_{2}\right]_{\mathrm{g}} / \mathrm{TiO}_{2}\right.$ and $\left.\mathrm{UV} /\left[\mathrm{H}_{2} \mathrm{O}_{2}\right]_{\mathrm{g}} / \mathrm{ZnO}\right)$, were used. However, it was found that the mineralization by $\mathrm{UV} /\left[\mathrm{H}_{2} \mathrm{O}_{2}\right]_{\mathrm{g}}$ significantly decreased, which in turn decreased the conductivity after the reaction. Increasing the pollutant concentration and the $\mathrm{pH}$ of the $\mathrm{H}_{2} \mathrm{O}_{2}$ had a negative effect on the treatment, but the UV radiation had a positive effect at powers of up to $40 \mathrm{~W}$. In addition, the characteristic absorbance of three benzene derivatives showed that the key structure of the pollutant molecules was damaged during GPAO.
\end{abstract}

Keywords Hydrogen peroxide vapour $\cdot$ Benzene series $\cdot$ Removal $\cdot$ Conductivity $\cdot$ Characteristic absorbance

\section{Introduction}

People need to breathe constantly, so nobody can avoid the influence of pollution. However, it is a widely recognized reality that air quality is not always good, especially in developing countries. Thus, pollution removal methods are increasingly studied. Such air pollution removal methods include adsorption, absorption, advanced oxidation (AO) and so on. Compared with other treatment methods, AO results in more complete and quicker removal of pollutants. Photochemical methods that do not require catalysts have received more attention in recent years (Alapi et al. 2007; Mo et al. 2009; Zhang and Anderson 2013) because there are

Responsible editor: Ricardo A. Torres-Palma

Yuping Jiang

jyp@zsc.edu.cn

1 University of Electronic Science and Technology of China, Zhongshan Institute, Zhongshan City 528403, Guangdong Province, China some distinctive advantages, such as energy efficiency and running costs, that must be evaluated for real-world applications (Matthew et al. 2014).

Both hydrogen peroxide and ozone are well-known oxidants that are usually used in aqueous and gaseous systems, respectively (Wang and Ray 2000). Although ozone is probably the leading oxidant species because its $2.07 \mathrm{~V}$ oxidation-reduction potential (ORP) is higher than that of hydrogen peroxide $1.8 \mathrm{~V}$, both substances can produce the - OH radical, which is regarded as the key oxidant in the AO process. Furthermore, $\mathrm{H}_{2} \mathrm{O}_{2}$ has multiple benefits. First, it is very easy to generate as long as electron donors are present in water, and chromophoric substances can produce hydrated electrons by illumination and combine with dissolved oxygen, which leads to a series of reactions for $\mathrm{H}_{2} \mathrm{O}_{2}$ outcome (Anastasio et al. 1997; Wohlgemuth et al. 2001). Second, artificial production of hydrogen peroxide is very convenient, even in situ production (Choudhary and Jana 2007; Fang et al. 2013). Third, $\mathrm{H}_{2} \mathrm{O}_{2}$ can be used as an indicator in the AO process because the representative oxidant, the hydroxyl radical $(\bullet \mathrm{OH})$, which has an (oxidation reduction potential) 
ORP of $2.8 \mathrm{~V}$, can lead to $\mathrm{H}_{2} \mathrm{O}_{2}$ formation by reacting with volatile organic compounds (VOCs), $\mathrm{CO}, \mathrm{SO}_{2}$, and other pollutants. It is evident that in AO involving multiple radical chain reactions, hydrogen peroxide plays a central role (Möeller 2009).

Due to its unique properties, $\mathrm{H}_{2} \mathrm{O}_{2}$ is usually used as an oxidative solution in tandem with ultraviolet (UV) radiation in AO processes to remove liquid pollutants (Xu et al. 2007; Muruganandham and Swaminathan 2004). Because the reactants are in solution during this process, the waste has a long residence time. For gas pollutant treatment, some studies have shown that $\mathrm{UV} / \mathrm{H}_{2} \mathrm{O}_{2}$ can oxidize $\mathrm{SO}_{2}, \mathrm{NOx}$ and $\mathrm{Hg}^{0}$ at low concentrations in flue gas (Yangxian et al. 2011; Yangxian et al. 2014). However, research focusing on GPAO by $\left[\mathrm{H}_{2} \mathrm{O}_{2}\right]_{\mathrm{g}}$ is very rare, especially that which involves a high pollutant concentration and short residence time, even if the vapour is only used for sterilization (French et al. 2004). In reality, the vapour form of $\mathrm{H}_{2} \mathrm{O}_{2}$ not only maintains the properties of the solution phase but also provides some advantages, such as a lesser oxidant consumption and decreased loss of UV light that passes through the reaction system.

In this work, the GPAO by $\mathrm{H}_{2} \mathrm{O}_{2}$ vapour was studied to understand the effect of harsh conditions, such as high concentration pollution and short residence time compared with those of related studies. The experiment was conducted to investigate the decomposition of benzene, toluene and xylene by $\mathrm{UV} /\left[\mathrm{H}_{2} \mathrm{O}_{2}\right]_{\mathrm{g}}$. The reactions took place in a transparent bag made of fluorinated ethylene propylene (FEP, Teflon) due to its high reactive inertia and UV transmittance (Du et al. 2007).

Benzene derivatives were chosen as the target compounds because such organic pollutants, including benzene, toluene and xylene, are frequently encountered, for example, benzene and toluene are frequently encountered in indoor and outdoor environments (Wallace et al. 1993; Bernstein et al. 2008), are representative organic contaminants (Liu et al.
2016) and can cause multiple diseases in humans. Research on pollutant removal methods includes adsorption, evaporation, membrane separation, microbial degradation and catalysis (Liu et al. 2018; Miaralipour et al. 2017; Varjani et al. 2017). However, GPAO is rarely used (Zhang et al. 2003; Johnson et al. 2014), and studies using $\mathrm{H}_{2} \mathrm{O}_{2}$ as an oxidant have not been reported.

\section{Experimental section}

\section{Materials and analysis}

The reagents were used as received without further treatment. Benzene, toluene, xylene, $\mathrm{NaOH}, \mathrm{HCl}$ and $30 \%$ commercial $\mathrm{H}_{2} \mathrm{O}_{2}$ solution (Guoyao Chemical Reagent Co., China) were analytical-grade reagents (AR). The powdered active carbon (PAC, $<75 \mu \mathrm{m}$ diameter, $0.45 \mathrm{~g} / \mathrm{cm}^{3}$ ), $\mathrm{ZnO}$ $\left(5.6 \mathrm{~g} / \mathrm{cm}^{3}\right)$ and $\mathrm{TiO}_{2}\left(4.28 \mathrm{~g} / \mathrm{cm}^{3}\right.$, anatase $)$ powder with a diameter of $20 \mathrm{~nm}$ and purity of $99.9 \%$ were separately purchased from Liyang Nanfang Activated Carbon Factory, Brofos Nanotechnology Ningbo Co., China.

\section{Experimental procedure}

The experimental system used in this study is illustrated in Fig. 1. All gas flow channels in the experimental system were FEP pipes. In this procedure, equal quantities of PAC, $\mathrm{TiO}_{2}$ and $\mathrm{ZnO}$ ( $2 \mathrm{~g}$ ) were added into compartment D, and air was pumped by a micro air pump (ACO-001, Guangzhou Weierma Instrument Co., Ltd. China) into the FEP pipes, regulated by rotameters to transfer the vapour of benzene and $\mathrm{H}_{2} \mathrm{O}_{2}$ to D. Here, the gas was thoroughly mixed with the powder due to the small particle size and low density of the powder. Then, the mixture was transferred to the FEP bag and irradiated under a UV lamp to undergo a
Fig. 1 Schematic of experimental system. Legend: A, air; B, liquid pollutant vessel; $\mathrm{C}, \mathrm{H}_{2} \mathrm{O}_{2}$ solution vessel; D, mixing tank; E, UV lamp (253.7 nm); F, FEP bag

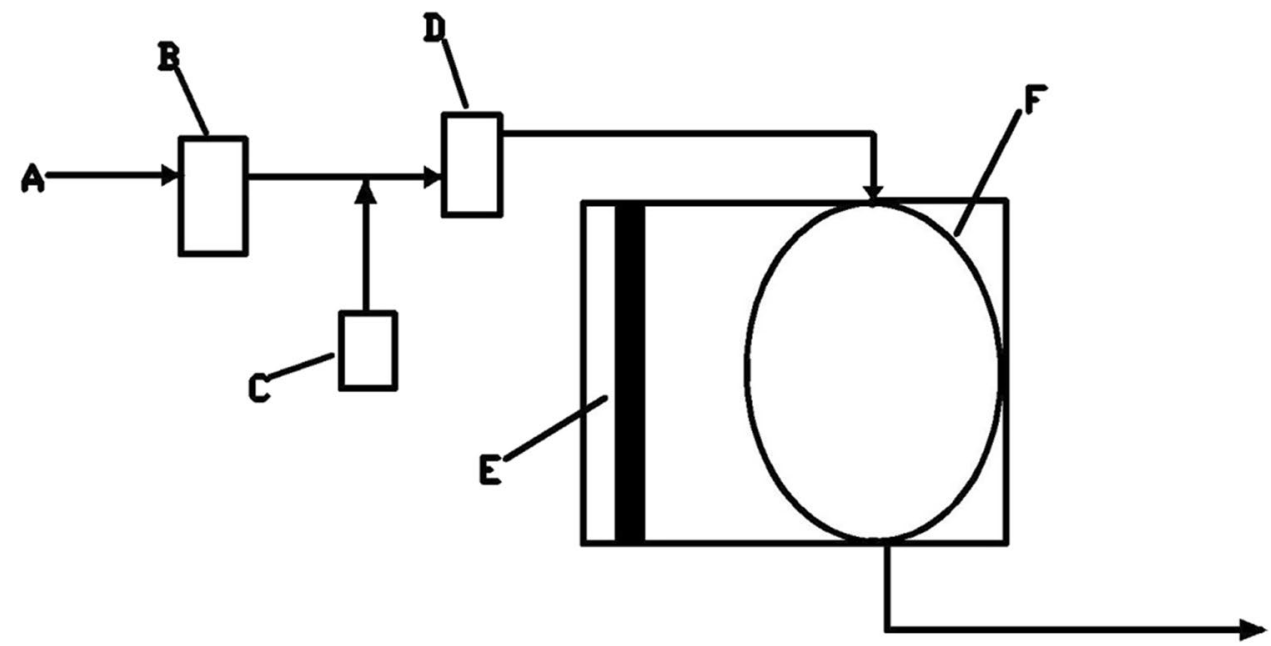


photochemical reaction. The inlet and outlet concentrations of the reactants were measured through the gas bypass line. To determine the apparent removal rate (dependent on the measurement for the pollutants), the pollutant concentrations were monitored via gas chromatography (GC) with FID and an AB-INOWAX fused silica capillary column (sampling time of 50-90 $\mathrm{min}$ ). The retention time was $1.2-1.6 \mathrm{~min}$ and was calculated by Eq. (1); the mineralization rate, which was dependent on the measurement of the terminal degradation product, was calculated with measurements from a $\mathrm{CO}_{2}$ detector (GT-1000- $\mathrm{CO}_{2}$, KORNO Co. Ltd. China). The characteristic absorbance of the pollutants and $\left[\mathrm{H}_{2} \mathrm{O}_{2}\right]_{\mathrm{g}}$ was determined by UV-vis spectroscopy and $\mathrm{H}_{2} \mathrm{O}_{2}$ detector (GT-1000- $\mathrm{H}_{2} \mathrm{O}_{2}$, KORNO Co. Ltd. China) separately. The apparent and mineralization efficiencies were calculated using Eqs. (2) and (3), respectively.

$\mathrm{C}\left(\mathrm{mg} / \mathrm{m}^{3}\right)=(\mathrm{A}-318.5) / 2.39$

Apparent removal efficiency $(\%)=\left(\mathrm{C}_{\mathrm{in}, \mathrm{p}}-\mathrm{C}_{\mathrm{out}, \mathrm{p}}\right) * 100 \% / \mathrm{C}_{\mathrm{in}, \mathrm{p}}$

Mineralization efficiency $(\%)=\left(\mathrm{C}_{\mathrm{out}, \mathrm{c}}-\mathrm{C}_{\mathrm{in}, \mathrm{c}}\right) * 100 \% / \mathrm{C}_{\mathrm{T}, \mathrm{c}}$

where $A$ is the peak area of the waste concentration determined by GC, and the correlation coefficient for (1) is 0.9997; $C$ is the concentration of the benzene derivative in $\mathrm{mg} / \mathrm{m}^{3} ; C_{i n, p}$ and $C_{\text {out }, p}$ are the inlet and outlet concentrations of pollutants, respectively; $C_{i n, c}$ and $C_{\text {out }, c}$ are the $\mathrm{CO}_{2}$ concentrations; and $C_{T, c}$ is the total $\mathrm{CO}_{2}$ concentration upon complete oxidation of the pollutant.

To investigate the effect of $\mathrm{pH}$ and conductivity, the $\mathrm{pH}$ of the $\mathrm{H}_{2} \mathrm{O}_{2}$ solution was adjusted by adding $\mathrm{HCl}$ and $\mathrm{NaOH}$ and was determined using an acidimeter (Model Starter 2100/3C Pro, Shanghai Hongji Instrument Co., Ltd. China). After $1 \mathrm{~h}$ of absorption in a $25-\mathrm{mL}$ opaque sampling tube with pure water, the conductivity was measured using a Conductivity Meter (DDSJ-319L, INESA Scientific Instrument Co., Ltd. China).

\section{Results and discussion}

\section{Effect of UV or $\mathrm{H}_{2} \mathrm{O}_{2}$ alone}

\section{Apparent removal by UV radiation}

Benzene was used as the target compound in these experiments. Figure 2 shows that with a maximum UV radiation power of $30 \mathrm{~W}$, benzene is resistant to removal under different reaction times, and the apparent removal rate was in the range of $0.5-1 \%$. There was little direct UV photo-oxidation and that which occurred was indirectly caused by substances

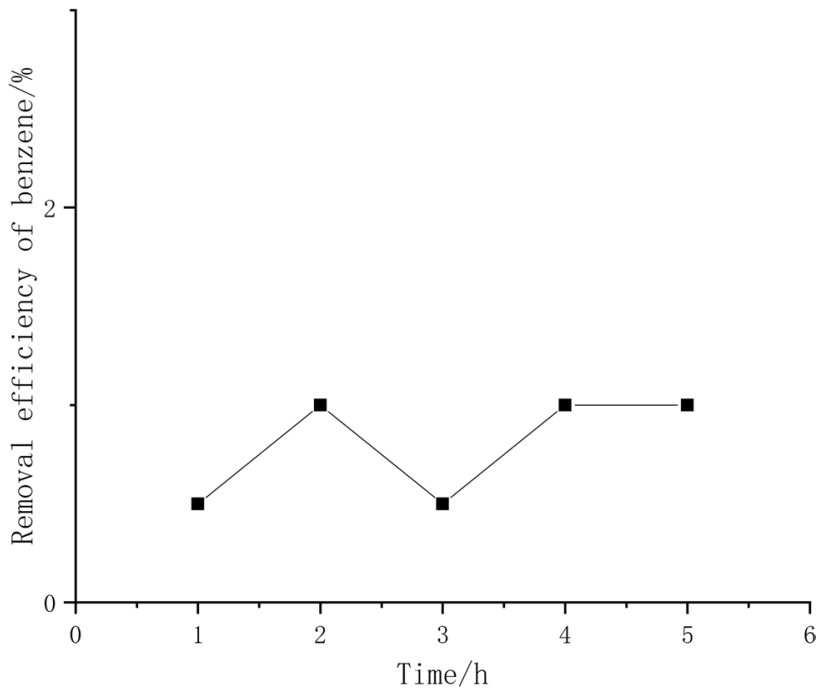

Fig. 2 Apparent removal of benzene when only UV radiation was applied

in the ambient air, such as $\mathrm{O}_{2}$ and $\mathrm{H}_{2} \mathrm{O}$. This observation is in accordance with studies showing that toluene and benzene in air could hardly be degraded under $>200 \mathrm{~nm} \mathrm{UV}$ light (Zhang et al. 2003; Zhuangzhuang et al. 2019) because $253.7 \mathrm{~nm}$ is too long of a wavelength to break the benzene molecular bond because the photons do not have enough energy. Although dimethylbenzene could be reduced under $254 \mathrm{~nm}$ light after a long time ( $>3 \mathrm{~h}$ ) (Ma et al. 2007), the substance is different from the benzene derivatives used in this study. In addition, it is critical to understand the impact of the reactor walls on gas-phase reactivity; due to the background NOx off-gas and other reactive species, heterogeneous reactions can generate "chamber radical sources" upon irradiation (Carter et al. 1982). However, Fig. 2 shows that the effects did not effectively influence pollutant reduction under certain conditions.

Conditions The experimental conditions were as follows: benzene concentration: $455 \mathrm{mg} / \mathrm{m}^{3}$; gas flow: $9 \mathrm{~L} / \mathrm{min}$; reactant temperature (room temperature): $25^{\circ} \mathrm{C}$; UV energy: $30 \mathrm{~W}$; and residence time: $3 \mathrm{~s}$.

\section{Apparent removal by $\left[\mathrm{H}_{2} \mathrm{O}_{2}\right]_{\mathrm{g}}$}

The performance of benzene oxidation with only $\left[\mathrm{H}_{2} \mathrm{O}_{2}\right]_{\mathrm{g}}$ was investigated without UV radiation. Figure 3 shows that the pollutant quantity decreased very slightly $(\leq 2 \%)$ over $5 \mathrm{~h}$ of reaction time; this result implies that although ambient light with very weak ultraviolet radiation could be transmitted into the reactor to cause $\left[\mathrm{H}_{2} \mathrm{O}_{2}\right]_{\mathrm{g}}$ to release $\cdot \mathrm{OH}$, the production of free radicals was too rare to enhance the reaction. Thus, the benzene was extremely inert and was not easily degraded by $\left[\mathrm{H}_{2} \mathrm{O}_{2}\right]_{\mathrm{g}}$ oxidation. This phenomenon also suggested that 


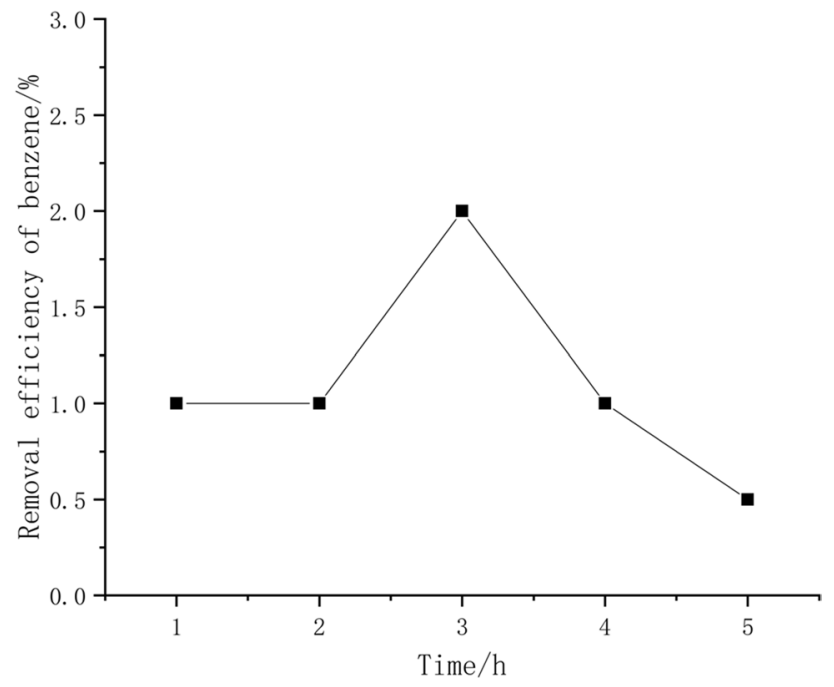

Fig. 3 Apparent removal of benzene with only $\left[\mathrm{H}_{2} \mathrm{O}_{2}\right]_{\mathrm{g}}$

generating hydroxyl radicals is necessary for GPAO. The results also show that the reactor was stable under $\left[\mathrm{H}_{2} \mathrm{O}_{2}\right]_{\mathrm{g}}$ oxidation. Other studies have proven that FEP Teflon bags meet the requirements of accuracy and small loss of gas due to photochemical reactions under different humidity, illumination, and substance conditions (Jia et al. 2011; Jia and Xu. 2014; Li et al. 2021). Therefore, based on the results of the test mentioned above, the reactor satisfactorily met the requirements of the study. However, Fig. 3 showed that after $3 \mathrm{~h}$ of treatment, the removal of benzene was the highest (2\%), while $5 \mathrm{~h}$ of treatment resulted in a lower inefficiency $(0.5 \%)$. According to the observations in this work, $\left[\mathrm{H}_{2} \mathrm{O}_{2}\right]_{\mathrm{g}}$ formed by $30 \%$ solution could slowly accumulate in the FEP pipe (not transparent) and bag (transparent). Therefore, when accumulation initially occurred in the pipe, the rate remained stable due to a lack of additional $\cdot \mathrm{OH}$ production in the reactor; then, when the accumulative $\mathrm{H}_{2} \mathrm{O}_{2}$ reached the bag, radicals could be generated to slightly enhance the reaction. However, with the increase in the substances accumulated on the bag wall, the transmission of the weak light was easily hindered, resulting in the subsequent decrease in the efficiency. After the reaction, the accumulation measurement for $\mathrm{H}_{2} \mathrm{O}_{2}$ was also carried out (Supplementary Information in Fig. S5).

Conditions The experimental conditions were similar to those in the "Apparent removal by UV radiation" section, in which $4.6 \mathrm{~mol} / \mathrm{m}^{3}\left[\mathrm{H}_{2} \mathrm{O}_{2}\right]_{\mathrm{g}}$ was used to replace the UV light.

\section{Apparent removal and mineralization}

\section{Apparent removal using different methods}

All four treatment methods could reduce the contaminants, as shown in Fig. 4. Although the maximal efficiency was

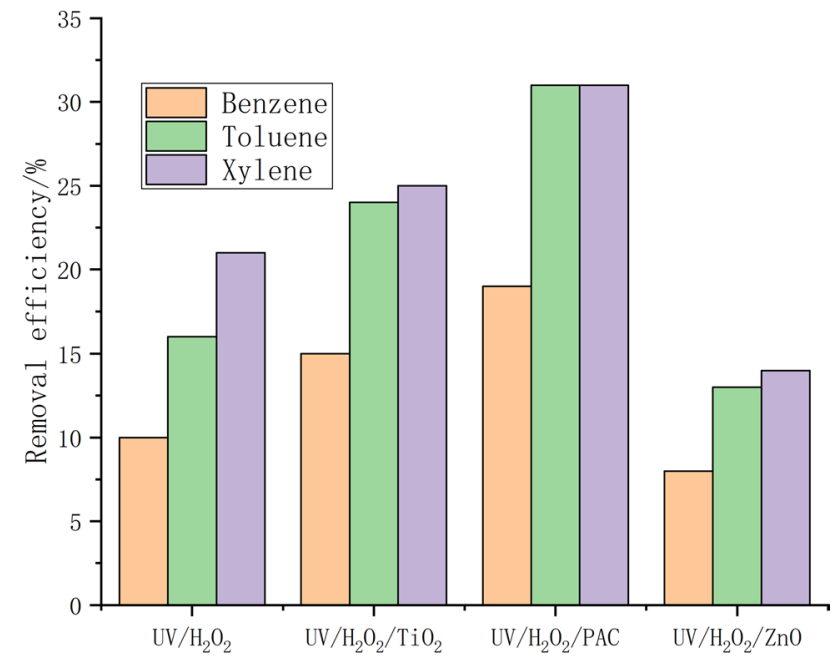

Fig. 4 Apparent removal rate by different pathways with $\mathrm{H}_{2} \mathrm{O}_{2}$

$31 \%$ for toluene, which is lower than that reported in related research (Yangxian et al. 2014; Xu et al. 2007), the toluene was obtained with a very short residence time and high concentration of pollutants. Thus, the result was still very meaningful, as $\left[\mathrm{H}_{2} \mathrm{O}_{2}\right]_{\mathrm{g}}$ played an important role as an oxidant. The fundamental role of $\mathrm{H}_{2} \mathrm{O}_{2}$ lies in its decomposition into. OH free radicals under UV radiation at a certain wavelength according to the following reaction (Lee et al. 2004).

$\mathbf{H}_{2} \mathbf{O}_{2}+h v \stackrel{\lambda<300 \mathrm{~nm}}{\longrightarrow} 2 . \mathbf{O H}$

Then, the removal of pollutants can be expressed by the following equations (Xu et al. 2007):

$$
\begin{aligned}
& . \mathrm{OH}+\text { Pollutant } \rightarrow \text { Intermediate } \\
& . \mathrm{OH}+\text { Intermediate } \rightarrow \mathrm{CO}_{2}+\mathrm{H}_{2} \mathrm{O}_{2}
\end{aligned}
$$

The catalyst and PAC completely left in the process, the determination of departure time and the subsequent removal after that time were also carried out (Supplementary Information in Table S1 and Fig. S4). In these three pathways, the potential problem was that $\mathrm{H}_{2} \mathrm{O}$ in the $\mathrm{H}_{2} \mathrm{O}_{2}$ vapour could hinder the removal because of its competitive adsorption onto the reaction surface of the contaminants (Herrmann et al. 1999; Nazir et al. 2003). However, some promotion of removal occurred in the process. In addition to the $\bullet \mathrm{OH}$ radical produced by $\mathrm{H}_{2} \mathrm{O}_{2}$, it was also produced by the two catalysts under $253.7 \mathrm{~nm}$ UV light. The electrons $\left(\mathrm{e}^{-}\right)$in the electron-filled valence band could be excited by photoirradiation (hv $>$ band gap energy) to the vacant conduction band, leaving a positive hole $\left(\mathrm{h}^{+}\right)$in the valence band; this $\mathrm{h}^{+}$caused the $\mathrm{OH}^{-}$from $\mathrm{H}_{2} \mathrm{O}$ oxidation to produce $\bullet \mathrm{OH}$, as shown in Eqs. (7) and (8). 
$\mathbf{T}_{\mathbf{i}} \mathbf{O}_{2}(\mathbf{Z n o})+\mathbf{h v} \rightarrow \mathbf{h}^{+}+\mathbf{e}^{-}$

$\mathbf{h}^{+}+\mathbf{O H}^{-} \rightarrow . \mathbf{O H}$

Then, $\bullet \mathrm{OH}$ could oxidize the compounds adsorbed on the surface of a photocatalyst. In addition, owing to the higher electron affinity of $\mathrm{H}_{2} \mathrm{O}_{2}(1.8 \mathrm{eV})$ than that of $\mathrm{O}_{2}(0.44 \mathrm{eV})$, the excited electrons in the conduction band could be captured by $\mathrm{H}_{2} \mathrm{O}_{2}$ more easily than by $\mathrm{O}_{2}$, which increased the production of $\bullet \mathrm{OH}$. Although the particle size of the PAC was the largest, its lowest density ensured ideal uniformity of mixing, and the adsorption performance could be helpful for removing pollutants, although the benzene derivatives were not completely degraded. There were fewer negative impacts of $\mathrm{TiO}_{2}$ and PAC than positive impacts, and the latter treatment is better for situations in which the adsorption surface area is very great. For the three pollutants, the desired enhanced effect of $\mathrm{ZnO}$ did not occur, but rather, the removal was less than when the other treatments were used. It was concluded that $\mathrm{ZnO}$ was prone to photocorrosion (Hoffmann et al. 1995; Han and Zhao 1999), and its density was highest, which caused deposition, leading to the shortcomings caused instability and heterogeneity during the reaction.

Conditions The experimental conditions were similar to those in the "Apparent removal by UV radiation" section, in which $4.6 \mathrm{~mol} / \mathrm{m}^{3}\left[\mathrm{H}_{2} \mathrm{O}_{2}\right] \mathrm{g}$ was also applied.

\section{Mineralization by $\mathrm{UV} /\left[\mathrm{H}_{2} \mathrm{O}_{2}\right]_{g}$}

In Fig. 5, it is shown that xylene had the highest apparent removal and mineralization rates, and benzene had the lowest. Toluene and xylene have one and two methyl groups substituting the hydrogen on the benzene ring, respectively; this substitution weakens the stability compared with that of benzene. These exocyclic groups are points that are easily attacked by oxidative species, which leads to the destruction of the whole molecular structure. Due to the greater number of methyl substitutions, the removal rate of xylene was most remarkable.

The results also showed that although the apparent removal rate was more than $10 \%$, the mineralization was very low; the maximum was less than $5 \%$. In general, the advanced oxidation by $\bullet \mathrm{OH}$ can be expressed as Eq. (9).

$$
. \mathrm{OH}+\text { pollutant } \rightarrow \text { intermediates } \rightarrow \mathrm{CO}_{2}+\mathrm{H}_{2} \mathrm{O}
$$

To remove the series of benzene derivatives, $\mathrm{C}=\mathrm{C}$ or $\mathrm{C}-\mathrm{H}$ were first cracked to form active organic radicals, and then the radicals continued to produce multiple fragments (intermediates), of which only some were oxidized to $\mathrm{CO}_{2}$ and $\mathrm{H}_{2} \mathrm{O}$; these observations were in accordance with those reported in multiple studies (Kuo-Pin and Grace 2007;

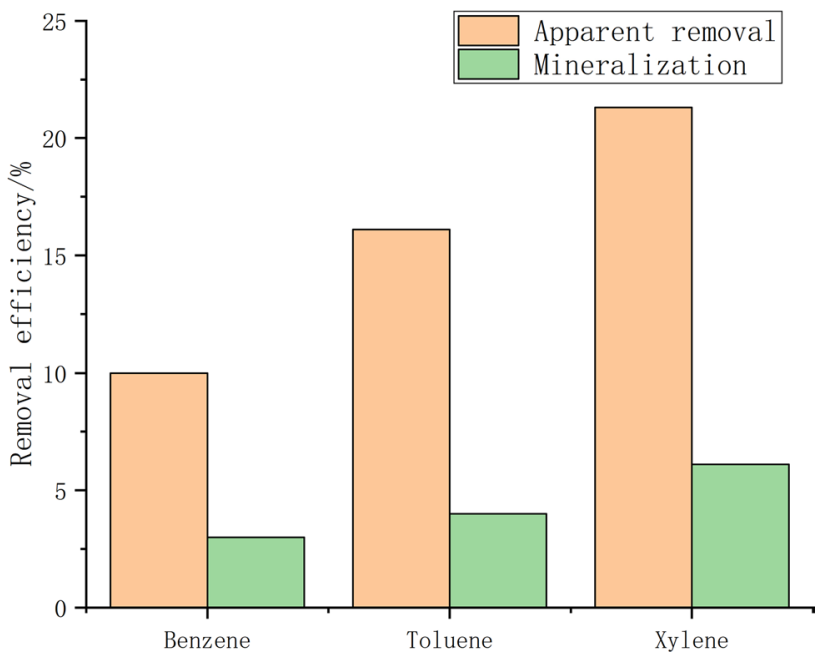

Fig. 5 Comparison between mineralization and apparent removal

Johnson et al. 2014). Due to the differences between the two measurement methods in this work, it was noted that most of the degraded pollutants did not mineralize, and the corresponding products were intermediates (not terminal degradation products), which caused a remarkable gap between the apparent removal and mineralization rates. For the other treatments with PAC and catalysts, similar results were also obtained (Supplementary Information in Fig. S1$\mathrm{PAC}, \mathrm{S} 2-\mathrm{TiO}_{2}$ and $\mathrm{S} 3-\mathrm{ZnO}$ ). These phenomena also revealed the limitations of GPAO, which cannot completely remove contaminants, hence limiting its applications.

Conditions The experimental conditions were in accordance with those described in the "Apparent removal using different methods" section.

\section{Characteristic absorbance}

Due to the multiple intermediate GPAO products, it is meaningful and necessary to focus on the characteristics of the molecules to determine whether pollutant structures are damaged. For the benzene derivatives, the conjugated ethylene in the benzene ring plays a directive role, and UV-Vis was used to investigate the inlet and outlet differences of the indicator. Although the benzene derivatives had a B-absorption band (230-270 nm) and E2 band (200-210 nm), the latter intensity was always higher than the former. Thus, E2 was used as the maximum absorbance in the experiment, and only the results of $\mathrm{UV} /\left[\mathrm{H}_{2} \mathrm{O}_{2}\right]_{\mathrm{g}}$ degradation are mentioned in Table 1. These results show that the wavelength and absorption intensity of toluene and xylene are higher than those of benzene because there were redshifts and hyperchromic effects. It is believed that the methyl groups in the two pollutants are auxochromes, and their electrons in the $\mathrm{n}$ orbital 
can produce a conjugation effect with $\pi$ electrons from the chromophores. Then, the electrons in the electron cloud can influence each other, which changes the absorption intensity and peak position ( $\mathrm{Li}$ et al. 2010). Table 1 also shows that there was a higher absorbance for inlet pollutants than for outlet pollutants. This phenomenon proved that it is also a feasible way to determine the removal effect. In addition, although this method involves a clear response to the conjugated ethylene in the benzene ring, it is rarely used in GPAO because the low concentrations of pollutants in the sample solution lead to very weak absorption peaks; in this work, this problem was solved by increasing the initial pollutant concentration and ending collection after longer sampling times.

Conditions The experimental conditions were in accordance with those in the "Apparent removal using different methods" section.

\section{Variation of conductivity}

In similar works, conductivity was not studied as the measurement index, although it can indicate changes in the substances after reaction. Figure 6 shows the conductivities of the inlet and outlet for removal of different pollutants. The data slightly decrease in the blank test (absorption by pure water), but opposite effects are observed with the pollutants. The result in the blank test could be explained by the fact that the UV decomposition of $\mathrm{H}_{2} \mathrm{O}_{2}$ caused its ionization reduction. For the latter measurement, Martina et al. found that the increase in polar products had a positive correlation with conductivity (Hein et al. 1998); therefore, it was believed that intermediates such as aldehydes, ketones and alcohols were polar products accelerated by the reaction and could not be completely eliminated due to the limited retention time. In addition, the increased values for benzene, xylene and toluene were 3.6, 1.2 and 0.2 , respectively. This result also indicated the difference in the quantity of polar intermediates, which is in accordance with some other studies (Kislov et al. 2004; Hamilton et al. 2005; Yu et al. 1997).

Conditions The experimental conditions were in accordance with those described in the "Apparent removal using different methods" section.

Table 1 characteristic absorbance by UV-Vis

\begin{tabular}{llcl}
\hline Pollutants & Benzene & Toluene & Xylene \\
\hline Characteristic Wavelength (nm) & 200 & 210.4 & 207.2 \\
Absorbance of inlet pollutant & 0.06813 & 0.0944 & 0.08744 \\
Absorbance of outlet pollutant & 0.02290 & 0.03012 & 0.05159 \\
\hline
\end{tabular}

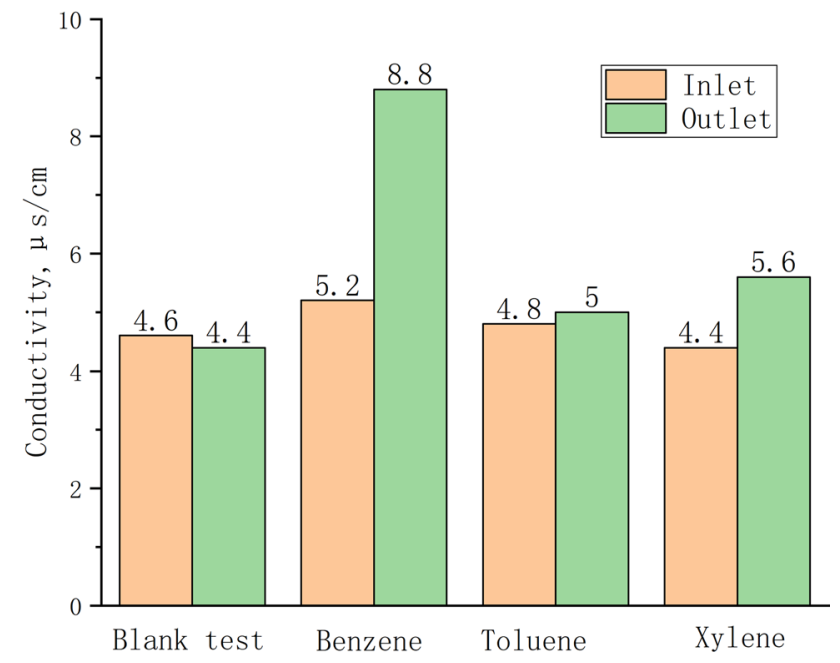

Fig. 6 Variation in conductivity for removal of different pollutants

\section{Effect by $\mathrm{pH}$ of $\mathrm{H}_{2} \mathrm{O}_{2}$}

Benzene vapour was selected to investigate the influence of $\mathrm{pH}$. The effect on the waste removal efficiency is shown in Fig. 7, in which the rate decreased from 28.6 to 1.7 as the $\mathrm{H}_{2} \mathrm{O}_{2}$ solution $\mathrm{pH}$ increased from 4 to 9 . It is widely recognized that $\mathrm{H}_{2} \mathrm{O}_{2}$ has stronger oxidizing properties under acidic conditions; therefore, the degradation was reduced with increasing solution $\mathrm{pH}$. For these reasons, some research has proven that $\mathrm{H}_{2} \mathrm{O}_{2}$ in solutions can produce $\mathrm{HO}_{2}{ }^{-}$species, which scavenge $\cdot \mathrm{OH}$ radicals via a hydrolysis reaction (Meng-Wen and Chia-Chun 2010; Liu et al. 2011). When the solution is alkaline, $\mathrm{OH}^{-}$can consume $\mathrm{H}^{+}$and accelerate $\mathrm{HO}_{2}^{-}$formation.

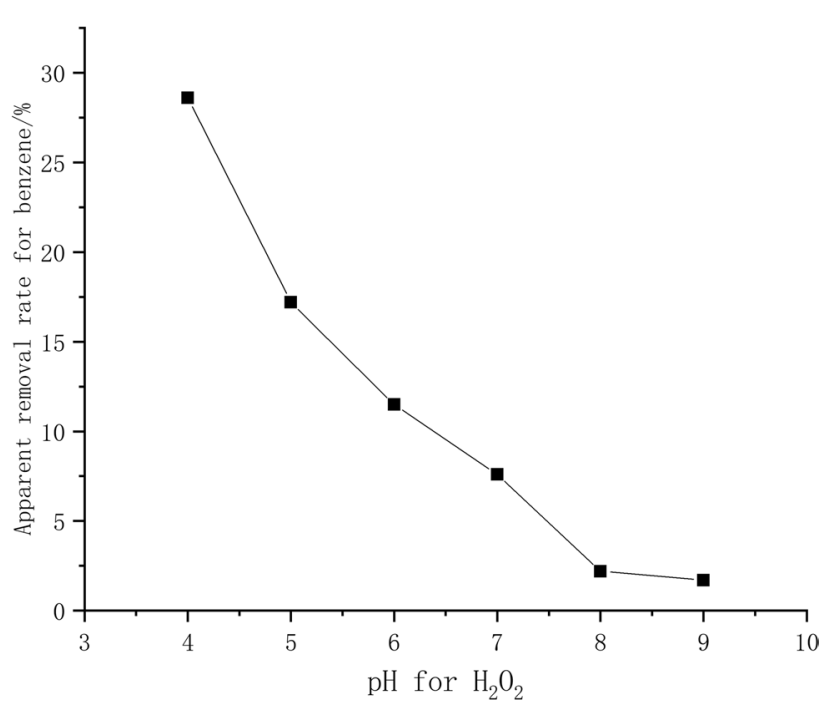

Fig. 7 Effect of $\mathrm{H}_{2} \mathrm{O}_{2} \mathrm{pH}$ for benzene removal 


$$
\mathbf{H}_{2} \mathrm{OH}_{2} \leftrightarrow \mathrm{HO}_{2^{-}}+\mathbf{H}^{+}
$$

$\mathrm{HO}_{2^{-}}+\cdot \mathrm{OH} \rightarrow \mathrm{H}_{2} \mathrm{O}+\mathrm{O}_{2^{-}}$

In addition, $\mathrm{OH}^{-}$can also consume $\cdot \mathrm{OH}$ radicals through the following reaction (Zehavi and Rabani 1971), thereby reducing the removal efficiency of benzene:

$\mathrm{OH}^{-}+\cdot \mathrm{OH} \rightarrow \mathrm{H}_{2} \mathrm{O}+\mathrm{O}_{2^{-}}$

Conditions Aside from the $\mathrm{pH}$, the experimental conditions were in accordance with those described in the "Apparent removal using different methods" section.

\section{Apparent removal by different UV power levels}

The influence of UV radiation was investigated at different UV powers, as shown in Fig. 8. The results show that the removal increases with increasing UV power at values from 10 to $40 \mathrm{~W}$. The improvement between 30 and $40 \mathrm{~W}$ was less than at lower power levels, and no improvement was observed from 40 to $50 \mathrm{~W}$. It could be deduced that the - OH concentration was increased when the UV intensity was increased; thus, the chain reactions were strengthened to obtain a higher reactant consumption rate (Anglada et al. 2002). However, when the UV radiation power exceeded a certain value, several side reactions (reactions 13-16) also simultaneously occurred in the system, resulting in the loss of $\cdot \mathrm{OH}$. Thus, with further increases in the light power to $40 \mathrm{~W}$, the pollutant removal efficiency only increased slightly and then did not change at $50 \mathrm{~W}$, which was the equilibrium state of the opposite action.

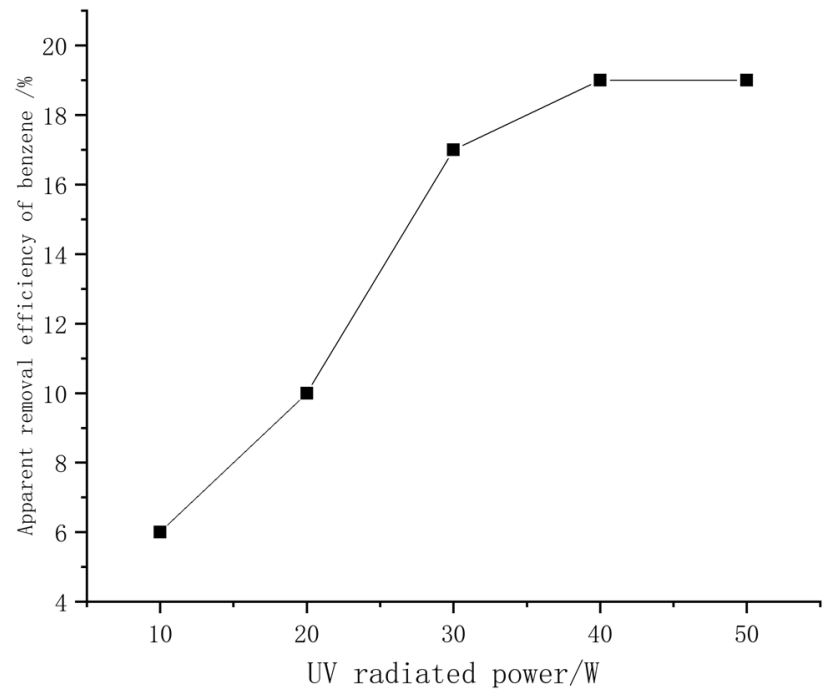

Fig. 8 Influence of UV power for benzene removal
$\mathrm{H}_{2} \mathrm{O}_{2}+\bullet \mathbf{O H} \rightarrow \mathrm{HO}_{2} \bullet+\mathrm{H}_{2} \mathrm{O}$

$\bullet \mathbf{O H}+\bullet \mathbf{O H} \rightarrow \mathrm{H}_{2} \mathrm{O}_{2}$

$\mathrm{HO}_{2} \bullet+\mathrm{HO}_{2} \bullet \rightarrow \mathrm{H}_{2} \mathrm{O}_{2}+\mathrm{O}_{2}$

$\bullet \mathrm{OH}+\mathrm{HO}_{2} \bullet \rightarrow \mathrm{H}_{2} \mathrm{O}+\mathrm{O}_{2}$

Conditions Aside from the UV light intensity, the other experimental conditions were in accordance with those described in the "Apparent removal using different methods" section.

\section{Effect of initial benzene concentration}

Under the same reaction conditions, benzene was used to study the effect of pollutant concentrations from 248 to $756 \mathrm{mg} / \mathrm{m}^{3}$ in the experiments. As shown in Fig. 9, the removal efficiency decreased when the initial concentration of benzene was increased. For a single chemical reaction system, according to the general theory, increasing the reactant concentration can raise the rate. However, in the photochemical reaction, improving the removal required more oxidants for degradation, and the higher oxidant concentrations were increasingly obstructive to UV radiation, causing the. $\mathrm{OH}$ to only be irradiated by a smaller amount of UV light, which led to the formation of fewer free radicals (Aleboyeh et al. 2005). Thus, the rate decreased.

Conditions Aside from the pollutant concentration, the other experimental conditions were in accordance with those

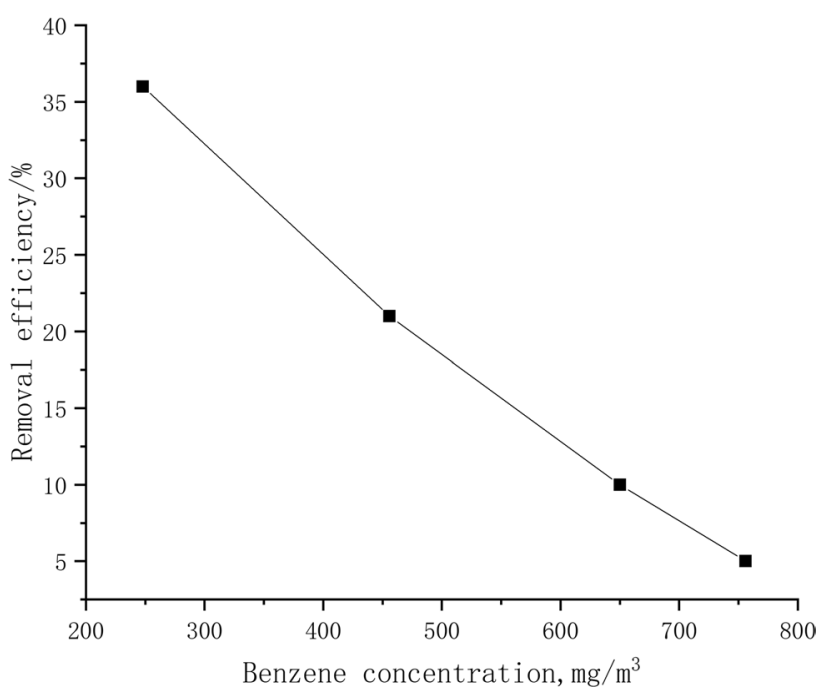

Fig. 9 Influence of concentration on benzene removal 
described in the "Apparent removal using different methods" section.

\section{Conclusion}

The reaction system, which included a reactor made of FEP film, $\left[\mathrm{H}_{2} \mathrm{O}_{2}\right]_{\mathrm{g}}$ as an oxidant, and UV light, was stable in the study and could also remarkably remove the benzene derivatives. In the present work, the reaction conditions were unfavourable compared with the conditions used in related studies. In particular, this study used shorter residence times and higher pollutant concentrations; thus, it was expected that with increasing reaction time, satisfactory efficiency would be obtained. In addition, it was very important to ensure the stability of the $\mathrm{H}_{2} \mathrm{O}_{2}$, pollution load and light transmittance; therefore, enhancing the power of the UV light and reducing the $\mathrm{pH}$ of the $\mathrm{H}_{2} \mathrm{O}_{2}$ solution and the pollutant concentration could improve the treatment effect in the experiment. In the GPAO experiments, although the characteristic structures of the benzene derivatives were destroyed, there were multiple intermediate polar products that caused the apparent removal rate to be much higher than the mineralization rate. Thus, it is necessary to further research the complete removal of waste.

Supplementary Information The online version contains supplementary material available at https://doi.org/10.1007/s11356-021-16920-w.

Acknowledgements The authors would like to thank the support by the Zhongshan Science and Technology Project (2019B2015) during the practical part of this work.

Author contribution Yuping Jiang analysed and interpreted the experiment and data of present study and was a major contributor in writing the manuscript; Juanjuan Song review the content of the article; Andong ZHU prepared the instrument for the experiment. All authors read and approved the final manuscript.

Funding This work was supported by the Zhongshan Science and Technology Project (2019B2015).

Availability of data and materials All data generated or analysed during this study are included in this published article.

\section{Declarations}

Ethics approval Not applicable.

Consent to participate Not applicable.

Consent to publication Not applicable.

Competing interests The authors declare no competing interests.

\section{References}

Alapi T, Craeynest KV, Langenhoeve HV, Dewulf J, Dombi A (2007) Direct vuv photolysis of chlorinated methanes and their mixtures in a nitrogen stream. Chemosphere 66(1):139-144

Aleboyeh A, Moussa Y, Aleboyeh H (2005) The effect of operational parameters on $\mathrm{UV} / \mathrm{H}_{2} \mathrm{O}_{2}$ decolourisation of acid blue 74. Dyes Pigm 66(2):129-134

Anastasio C, Faust BC, Rao CJ (1997) Aromatic carbonyl compounds as aqueous-phase photochemical sources of hydrogen peroxide in acidic sulfate aerosols, fogs, and clouds. 1. nonphenolic methoxybenzaldehydes and methoxyacetophenones with reductants (phenols). Environ Sci Technol 31(1):218-232

Anglada JM, Aplincourt P, Bofill JM, Cremer D (2002) Atmospheric formation of $\mathrm{OH}$ radicals and $\mathrm{H}_{2} \mathrm{O}_{2}$ from alkene ozonolysis under humid conditions. ChemPhysChem 3(2):215-221

Bernstein JA, Alexis N, Bacchus H, Bernstein IL, Fritz P, Horner E (2008) The health effects of non-industrial indoor air pollution. J Allergy Clin Immunol 121(3):585-591

Carter WPL, Atkinson R, WinerPitts AMJN Jr (1982) Experimental investigation of chamber-dependent radical sources. Int J Chem Kinet 14(10):1071-1103

Chang MW, Chung CC, Chern JM, Chen TS (2010) Dye decomposition kinetics by uv/h2o2: initial rate analysis by effective kinetic modelling methodology. Chem Eng Sci 65(1):135-140

Choudhary VR, Jana P (2007) In situ generation of hydrogen peroxide from reaction of $\mathrm{O}_{2}$ with hydroxylamine from hydroxylammonium salt in neutral aqueous or non-aqueous medium using reusable $\mathrm{Pd} / \mathrm{Al}_{2} \mathrm{O}_{3}$ catalyst. Catal Commun 8(11):1578-1582

Du L, Xu Y, Ge M, Jia L, Wang G, Wang D (2007) Smog chamber simulation of atmospheric photochemical reactions of acetylene and NOx. Environ Sci 28(3):482-488

Fang GD, Zhou DM, Dionysiou DD (2013) Superoxide mediated production of hydroxyl radicals by magnetite nanoparticles: demonstration in the degradation of 2-chlorobiphenyl. J Hazard Mater 250:68-75

French GL, Otter JA, Shannon KP, Adams NMT, Watling D, Parks MJ (2004) Tackling contamination of the hospital environment by methicillin-resistant staphylococcus aureus (mrsa): a comparison between conventional terminal cleaning and hydrogen peroxide vapour decontamination. J Hosp Infect 57(1):31-37

Hamilton JF, Webb PJ, Lewis AC, Reviejo MM (2005) Quantifying small molecules in secondary organic aerosol formed during the photo-oxidation of toluene with hydroxyl radicals. Atmos Environ 39(38):7263-7275

Han Z, Zhao H (1999) Progress in applied research of the heterogeneous photocatalysis on semiconductors $[\mathrm{J}]$. Prog Chem (in Chinese) 11(1):1-10

Hein M, Henning H, Isengard HD (1998) Determination of total polar parts with new methods for the quality survey of frying fats and oils. Talanta 47(2):447-454

Herrmann JM, Matos J, Disdier J, Guillard C, Blanco J (1999) Solar photocatalytic degradation of 4-chlorophenol using the synergistic effect between titania and activated carbon in aqueous suspension. Catal Today 54(2):255-265

Hoffmann MR, Martin ST, Choi W, Bahnemann DW (1995) Environmental applications of semiconductor photocatalysis. Chem Rev 95(1):69-96

Jia L, Xu YF (2014) Studies of ozone formation potentials for benzene and ethylbenzene using a smog chamber and model simulation. Huan Jing Ke Xue 35(2):495-503

Jia L, Xu Y, Shi Y (2011) Characterization of photochemical smog chamber and initial experiments. Huan Jing Ke Xue 32(2):351-361 
Johnson MS, Nilsson EJK, Svensson EA, Langer S (2014) Gas-phase advanced oxidation for effective, efficient in situ control of pollution. Environ Sci Technol 48(15):8768-8776

Kislov VV, Nguyen TL, Mebel AM, Lin SH, Smith SC (2004) Photodissociation of benzene under collision-free conditions: an ab initio/rice-ramsperger-kassel-marcus study. J Chem Phys 120(15):7008-7017

Kuo-Pin Y, Grace WML (2007) Decomposition of gas-phase toluene by the combination of ozone and photocatalytic oxidation process $\left(\mathrm{TiO}_{2} / \mathrm{UV}, \mathrm{TiO}_{2} / \mathrm{UV} / \mathrm{O}_{3}\right.$, and $\left.\mathrm{UV} / \mathrm{O}_{3}\right)$. Appl Catal B 75:29-38

Lee Y, Lee C, Yoon J (2004) Kinetics and mechanisms of dmso (dimethylsulfoxide) degradation by $\mathrm{UV} / \mathrm{H}_{2} \mathrm{O}_{2}$ process. Water Res 38(10):2579-2588

Li MX, He XS, Liu J (2010) Study on the characteristic UV absorption parameters of dissolved organic matter extracted from chicken manure during composting. Spectrosc Spectr Anal 30(11):3081-3085

Li J, Li H, Wang X, Wang W, Liu Y (2021) A large-scale outdoor atmospheric simulation smog chamber for studying atmospheric photochemical processes: characterization and preliminary application. J Environ Sci 102(5):185-197

Liu Y, Zhang J, Sheng C (2011) Study on the kinetics of no removal from simulated flue gas by a wet ultraviolet $/ \mathrm{H}_{2} \mathrm{O}_{2}$ advanced oxidation process. Energy Fuels 25(4):1547-1552

Liu H, Bruton TA, Li W, Buren JV, Sedlak DL (2016) Oxidation of benzene by persulfate in the presence of $\mathrm{Fe}(\mathrm{III})$ - and $\mathrm{Mn}(\mathrm{IV})-$ containing oxides: stoichiometric efficiency and transformation products. Environ Sci Technol 50(2):890-898

Liu HX, Wang N, Cui Z, Ji S, Li JR (2018) Membrane materials in the pervaporation separation of aromatic/aliphatic hydrocarbon mixtures-a review. Chin J Chem Eng 26(1):1-16

Ma G, Yin Y, Wang S (2007) Degradation of xylene in gas phase by ozone and UV light. J Shandong Jianzhu Univ 22(1):57-60

Matthew SJ, Elna JK, Nilsson Erik AS, Sarka L (2014) Gas-Phase Advanced Oxidation for Effective, Efficient in Situ Control of Pollution. Environmental Science \& Technology, 48: 8768-8776

Meng-Wen C, Chia-Chun C (2010) Dye decomposition kinetics by UV/ $\mathrm{H}_{2} \mathrm{O}_{2}$ : initial rate analysis by effective kinetic modelling methodology. Chem Eng Sci 65(1):135-140

Miaralipour S, Friedmann D, Scott J, Amal R (2017) $\mathrm{TiO}_{2}$ /porous adsorbents: recent advances and novel applications. J Hazard Mater 341:404-423

Mo J, Zhang Y, Xu Q, Lamson JJ, Zhao R (2009) Photocatalytic purification of volatile organic compounds in indoor air: a literature review. Atmos Environ 43(14):2229-2246

Möeller D (2009) Atmospheric hydrogen peroxide: evidence for aqueous-phase formation from a historic perspective and a one-year measurement campaign. Atmos Environ 43(37):5923-5936

Muruganandham M, Swaminathan M (2004) Photochemical oxidation of reactive azo dye with $\mathrm{UV}-\mathrm{H}_{2} \mathrm{O}_{2}$ process. Dyes Pigm 62(3):269-275
Nazir M, Takasaki J, Kumazawa H (2003) Photocatalytic degradation of gaseous ammonia and trichloroethylene over $\mathrm{TiO}_{2}$ ultrafine powders deposited on activated carbon particles. Chem Eng Commun 190(3):322-333

Varjani SJ, Gnansounou E, Pandey A (2017) Comprehensive review on toxicity of persistent organic pollutants from petroleum refinery waste and their degradation by microorganisms. Chemosphere 188:280-291

Wallace L, Hartwell T, Pellizzari E (1993) Personal exposures, indooroutdoor relationships, and breath levels of toxic air pollutants measured for 355 persons in new jersey. Atmos Environ A Gen Top 27(14):2245-2247

Wang JH, Ray MB (2000) Application of ultraviolet photooxidation to remove organic pollutants in the gas phase. Sep Purif Technol 19(1-2):11-20

Wohlgemuth J, Dagmar P, Jaeschke W, Deutsch F, Hoffmann P, Ortner HM (2001) Photochemical formation of hydrogen peroxide in atmospheric droplets: the role of iron, oxalate, and trace metals of the $\mathrm{H}_{2} \mathrm{O}_{2}$-production. Phys Rev D Part Fields 37(4):1097-1098

Xu B, Gao NY, Sun XF, Xia SJ, Rui M, Simonnot MO (2007) Photochemical degradation of diethyl phthalate with $\mathrm{UV} / \mathrm{H}_{2} \mathrm{O}_{2}$. J Hazard Mater 139(1):132-139

Yangxian L, Jun Z, Changdong S (2011) Kinetic model of NO removal from $\mathrm{SO}_{2}$-containing simulated flue gas by wet $\mathrm{UV} / \mathrm{H}_{2} \mathrm{O}_{2}$ gasphase advanced oxidation process. Chem Eng J 168(1):183-189

Yangxian L, Jun Z, Jianfeng P (2014) Photochemical oxidation removal of $\mathrm{Hg} 0$ from flue gas containing $\mathrm{SO} 2 / \mathrm{NO}$ by an ultraviolet irradiation/hydrogen peroxide (UV/H2O2) Process. Energy Fuels 28(3):2135-2143

Yu J, Jeffries HE, Sexton KG (1997) Atmospheric photooxidation of alkylbenzenes-i. carbonyl product analyses. Atmos Environ 31(15):2261-2280

Zehavi D, Rabani J (1971) Pulse radiolytic investigation of $\mathrm{O}_{\mathrm{aq}}{ }^{-}$radical ions. J Phys Chem 75:1738-1744

Zhang L, Anderson WA (2013) Kinetic analysis of the photochemical decomposition of gas-phase chlorobenzene in a uv reactor: quantum yield and photonic efficiency. Chem Eng J 218:247-252

Zhang P, Liang F, Chen Q, Yu G, Zhu W (2003) photocatalytic degradation of low level toluene in the gas phase. Huanjing Kexue 24(6):54-58

Zhuangzhuang F, Mingqiang H, Jun XU, Shunyou C, Weixiong Z, Changjin HU (2019) Experimental study of the secondary organic aerosol formed from the aqueous photooxidation of benzene. Acta Sci Circum 39(7):2362-2368

Publisher's note Springer Nature remains neutral with regard to jurisdictional claims in published maps and institutional affiliations. 